\title{
Identifying and Localizing Intracellular Nanoparticles Using Raman Spectroscopy
}

Jennifer Dorney

Technological University Dublin, jennifer.dorney@tudublin.ie

Franck Bonnier

Technological University Dublin, Franck.Bonnier@tudublin.ie

Amaya Garcia

Technological University Dublin

See next page for additional authors

Follow this and additional works at: https://arrow.tudublin.ie/radart

Part of the Physics Commons

\section{Recommended Citation}

Dorney, J. et al (2012) Identifying and Localizing Intracellular Nanoparticles Using Raman Spectroscopy. Analyst, Mar 7;137(5) pp.1111-9. doi:10.1039/C2AN15977E

This Article is brought to you for free and open access by the Radiation and Environmental Science Centre at ARROW@TU Dublin. It has been accepted for inclusion in Articles by an authorized administrator of ARROW@TU Dublin. For more information, please contact arrow.admin@tudublin.ie, aisling.coyne@tudublin.ie, gerard.connolly@tudublin.ie.

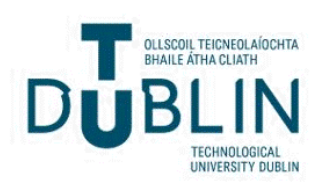




\section{Authors}

Jennifer Dorney, Franck Bonnier, Amaya Garcia, Alan Casey, Gordon Chambers, and Hugh Byrne

This article is available at ARROW@TU Dublin: https://arrow.tudublin.ie/radart/35 
Identifying and localizing intracellular nanoparticles using Raman

Spectroscopy:

\author{
Jennifer Dorney $^{1,2}$, Franck Bonnier ${ }^{3 *}$, Amaya Garcia ${ }^{3}$, Alan Casey ${ }^{1}$, Gordon Chambers ${ }^{1,2}$, \\ Hugh J. Byrne ${ }^{1}$
}

1. Nanolab Research Centre, Focas Research Institute, Dublin Institute of Technology

(DIT), Camden Row, Dublin 8, Ireland

2. School of Physics, Dublin Institute of Technology (DIT), Kevin Street,

Dublin 8, Ireland

\title{
3. Radiation and Environmental Science Centre, Dublin Institute of Technology (DIT), Camden Row, Dublin 8, Ireland
}

\begin{abstract}
Raman microscopy is employed to spectroscopically image biological cells previously exposed to fluorescently labelled polystyrene nanoparticles and, in combination with Kmeans clustering and Principal Component Analysis (PCA), is demonstrated to be capable of localising the nanoparticles and identifying the subcellular environment based on the molecular spectroscopic signatures. The neutral nanoparticles of $50 \mathrm{~nm}$ or $100 \mathrm{~nm}$, as characterised by dynamic light scattering, are shown to be non-toxic to a human lung adenocarcinoma cell-line (A549), according to a range of cytotoxicity assays including Neutral Red, Alamar Blue, Coomassie Blue and (3-(4,5-Dimethylthiazol-2-yl)-2,5diphenyltetrazolium bromide (MTT). Confocal fluorescence microscopy identifies intracellular fluorescence due to the nanoparticle exposure, but the fluorescence distribution is spatially diffuse, potentially due to detachment of the dye from the nanoparticles, and the technique fails to unambiguously identify the distribution of the nanoparticles within the cells. Raman spectroscopic mapping of the cells in combination with K-means cluster analysis is used to clearly identify and localise the polystyrene nanoparticles in exposed cells, based on their characteristic spectroscopic signatures. PCA identifies the local environment as rich in lipidic signatures which are associated with localisation of the nanoparticles in the endoplasmic reticulum. The importance of optimised cell growth conditions and fixation processes is highlighted. The preliminary study demonstrates the potential of the technique to unambiguously identify and locate nonfluorescent nanoparticles in cells and to probe not only the local environment but also changes to the cell metabolism which may be associated with cytotoxic responses.
\end{abstract}


Keywords: Nanopolystyrene; Nanoparticle Internalisation; Cytotoxicity; Confocal Fluorescence; Raman Spectroscopy; Live cell imaging; K-means Cluster Analysis; Principal Component Analysis

* Corresponding author. Tel.: +353 1 4027917; Fax: +353 1 4027904;

E-mail address: franck.bonnier@dit.ie(F. Bonnier) 


\section{Introduction}

One of the major concerns regarding the possible toxic effects of nanoparticles is the capacity of these materials to penetrate cells and possibly translocate to other cells around the body. Conventional in vitro cytotoxicity assays, such as Alamar Blue, Neutral Red, MTT, etc, provide indications of impact on cell proliferation, viability, metabolic activity, lysosomal and mitochondrial activity. However, they fail to provide a verification of nanoparticle internalisation or elucidate intracellular trafficking mechanisms and subcellular distribution within cells. Indeed, false positive results have been demonstrated due to the extracellular interaction of the nanoparticles with the cell culture medium in vitro, and with the cytotoxic assays themselves. ${ }^{1,2}$ The underlying principles of internalisation and distribution of nanoparticles within cells and any associated toxicity to humans are still relatively poorly understood. However, there are numerous studies that have demonstrated the ability of nanoparticles to cross membranes and internalise within many different cell types. ${ }^{3-5}$ In order to assess potential risks, but also benefits in terms of nanomedicine, a greater understanding of migration of nanoparticles intra- and intercellularly and essentially from one part of the body to another, along with information on the translocation of nanoparticles within organelles, is urgently required.

Among the main challenges faced by nanotoxicologists are the detection and identification of nanoparticles that have crossed the cell membrane and monitoring of their intracellular trafficking. Imaging cells exposed to fluorescently labelled nanoparticles using confocal fluorescence microscopy is one of the most common ways in which to ensure nanoparticles can be tracked and monitored as they enter and localise within cells. $^{6-8}$ However, not all nanoparticles can be easily fluorescently labelled. 
Furthermore, there have been reports that labelled nanoparticles can release the dye into the surrounding biological environment, and so the distribution of fluorescence within the cell does not necessarily represent the presence or subcellular distribution of the nanoparticles. ${ }^{9-11}$ Furthermore, it is not clear that the transport mechanisms of smaller nanoparticles, fluorescently labelled with anionic moieties, are the same as their unlabelled counterparts. For example, it has been reported that extrinsic labelling of bovine serum albumin (BSA) with fluorescein-5-isothiocyanate (FITC), in a ratio of 2:1, changes its adsorption and diffusion properties. ${ }^{12}$ Transmission Electron Microscopy can also be employed to visualise nanoparticles within cells, but significant sample processing (fixing and ultramicrotoming) is required and only particles with sufficient electronic contrast to the cellular environment can be visualised. ${ }^{13,14}$ Thus, there is a requirement for a sensitive technique to localise and identify nanoparticles internalised in cells, ideally based on their chemical composition, rather than fluorescence labels or electronic contrast. Identification of their local environment (e.g. endosomes, lysosomes, mitochondria) could aid in elucidating their intracellular trafficking and interaction mechanisms, and the resulting changes in cellular metabolism.

Raman spectroscopy has been proposed as a potential technique for in vitro screening of the interaction of nanoparticles with cells. ${ }^{15}$ Raman is well established for chemically fingerprinting materials, with applications in, for example, forensics and the pharmacological industry. ${ }^{16-19}$ More recently, it has been explored for the analysis of disease and, when coupled with multivariate statistical analysis, has shown high sensitivity and specificity for diagnostic applications. ${ }^{20,21}$ Raman microspectroscopy also presents several advantages for the study of live cells, combining molecular analysis with 
optical imaging. In comparison to infrared spectroscopic analysis, the weak contribution from water offers the possibility to study the cells in an aqueous environment, maintaining viability for the duration of the measurement. ${ }^{22}$ The specific information contained in the Raman spectrum of the cells or subcellular compartments provides a signature of the sample studied which can be related to molecular content or changes to the physiology as a result of external stimuli. ${ }^{23-28}$ In confocal microscopic mode, the spatial resolution is of the order of $\leq 1 \mu \mathrm{m}$, depending on source wavelength, providing access to the subcellular organisation of the cells. ${ }^{29,} 30$ Thus, Raman spectroscopy potentially offers a label free probe of nanoparticles within cells, which can potentially analyse their local environment, and ultimately changes in the cellular metabolism which can be correlated with cytotoxic responses ${ }^{31}$, oxidative stress, or inflammation. Kneipp et al. have previously demonstrated the use of Surface Enhanced Raman Scattering from gold nanoparticles and nanoaggregates to probe the environment of the subcellular compartments through which they are trafficked. ${ }^{32} 33$ They have also demonstrated the use of molecular labelled nanoparticles as more specific probes of the local environment. ${ }^{34-36}$ However, the uptake rates and mechanisms as well as the subsequent trafficking may be specific to the nanoparticle type, size and surface chemistry. Furthermore, the molecular specificity of the surface enhancement process is not well understood. Therefore, a truly label free method for monitoring and characterising the cellular uptake and subcellular localisation of nanoparticles in general is still required.

In this study, Raman spectroscopy will be evaluated for the label free detection and localisation of nanoparticles at the subcellular level. Polystyrene nanoparticles, labelled for parallel fluorescence uptake studies, are employed. Common cytotoxic assays show 
no observed effect over the concentration range studied. Confocal fluorescence microscopy indicates internalisation of the fluorescent label within the cells, but the spatially diffuse distribution does not allow unambiguous localisation of the nanoparticles. It is demonstrated that, based on spectroscopic fingerprint of polystyrene, Raman spectroscopy, coupled with routine multivariate analyses such as K-means clustering, is a more specific probe to detect and localise the particles. Furthermore, Principal Component Analysis can be employed to differentiate the local environment of the nanoparticles from the cytoplasm.

The importance of optimised cell culture conditions and fixation procedures is highlighted, but ultimately, this work suggests the potential of Raman spectroscopy not only to detect and identify nanoparticles within the cellular environment, but also to identify their subcellular environment and changes to the cellular metabolism which underlie toxic responses.

\section{Materials and methods}

\subsection{Nanoparticles}

“Fluorescent Microsphere Suspensions” of $50 \mathrm{~nm}$ and $100 \mathrm{~nm}$ polystyrene beads were purchased from Duke Scientific Corporation, (now Thermo Scientific USA http://www.thermoscientific.com). Particle size measurements and zeta potential measurements were carried out in the respective media (distilled water and cell culture medium) as described in the Supplementary Information (S.1).

\subsection{A549 Cell lines}


A549 cells from a human lung adenocarcinoma with the alveolar type II phenotype were obtained from ATTC (Manassas, VA, USA). Cells were cultured in DMEM-F12 (Lonza, Wokingham, UK) supplemented with L-glutamine and 10\% foetal calf serum (FCS, Lonza, Wokingham, UK) in a humidified atmosphere containing $5 \% \mathrm{CO}_{2}$ at $37{ }^{\circ} \mathrm{C}$.

\subsection{Cytotoxicity assays}

A range of colorimetric cytotoxicity assays were conducted to establish the effects of exposure of the A549 cells to the nanoparticles and the details are provided in the Supplementary Information (S.2).

\subsection{Sample preparation for imaging}

Approximately 40,000 cells were seeded onto either $35 \mathrm{~mm}$ uncoated glass bottom dishes (MatTek Corporation, USA) for confocal imaging or $\mathrm{CaF}_{2}$ windows (Crystran Ltd., UK) for Raman acquisitions. The cells were incubated in 10\% FCS DMEM-F12 media at $37^{0} \mathrm{C}$ for $24 \mathrm{hr}$ before observation with confocal microscopy. Media was then removed and samples were rinsed with sterile PBS and kept in $0.2 \mu \mathrm{m}$ sterile filtered $0.9 \% \mathrm{NaCl}$ saline solution for imaging.

Samples for confocal fluorescence imaging were obtained by seeding cells on $35 \mathrm{~mm}$ uncoated glass bottom dishes (Mat Tek Corporation, USA), as described above. Cells were allowed to attach for approximately 4 hrs, after which $2 \mathrm{mls}$ of $10 \%$ FCS RPMI media were added, containing $1 \times 10^{12}$ nanoparticles per ml of media. Exposure times before imaging ranged from 4 hrs to $24 \mathrm{hrs}$. 
For Raman analysis, A549 cells were seeded on $\mathrm{CaF}_{2}$ windows as described above and allowed to attach for approximately 4 hrs, after which $2 \mathrm{mls}$ of 10\% FCS RPMI media were added, containing $1 \times 10^{12}$ nanoparticles per $\mathrm{ml}$ of media. Plates were left in an incubator over night for 24 hrs. Media was then removed and samples were rinsed with sterile PBS and kept in sterile $0.2 \mu \mathrm{m}$ filtered $0.9 \% \mathrm{NaCl}$ saline solution for imaging.

As the Raman mapping of single cells can take up to a few hours using a $785 \mathrm{~nm}$ laser source, the cells were fixed using formalin. Thus, the stability of the sample compared to live cells is greatly improved, allowing the collection of spectra precisely from the selected area. After washing the $\mathrm{CaF}_{2}$ windows using PBS, the samples were immersed in $10 \%$ formalin for 10 mins for fixation. After fixation, the samples were washed thrice in PBS to remove any trace of the fixative and kept in $\mathrm{NaCl}$ for measurement.

For comparison of cellular spectra to constituent biochemical components, five different compounds were prepared for Raman spectroscopy analysis: Raman spectra were recorded from lyophilised DeoxyriboNucleic Acid from calf thymus deposited on $\mathrm{CaF}_{2}$ substrates. Ribonucleic acid from baker's yeast (S. cerevisiae) was first suspended in water and deposited onto $\mathrm{CaF}_{2}$ substrates for drying before recording. Sphingomyelin from bovine brain and L- $\alpha$-Phosphatidylcholine from egg yolk were first dispersed in chloroform and then deposited onto $\mathrm{CaF}_{2}$ substrates and left to dry before spectral acquisition. A few micro-litres of the nanoparticles suspension were deposited on a $\mathrm{CaF}_{2}$ and air dried before recording.

\subsection{Confocal Fluorescence imaging of cells}


In order to compare the cell morphologies, samples were imaged using the white light mode of an inverted Zeiss LSM510 confocal laser scanning microscope (Carl Zeiss Inc.) equipped with an x60 oil immersion objective. For nanoparticle exposed samples, fluorescence images were captured at room temperature using an inverted Zeiss LSM510 confocal laser scanning microscope (Carl Zeiss Inc.). The excitation wavelength used was $488 \mathrm{~nm}$, set at $4 \%$ of laser power and the fluorescence emission was detected using a $505 \mathrm{~nm}$ long pass filter. Images were obtained with a 60x oil immersion objective.

\subsection{Confocal Fluorescence imaging of cell organelles}

The CellLight ${ }^{\circledR}$ reagent, purchased from Invitrogen, was employed to image the subcellular components of the cells. It contains a baculovirus that, upon entry into mammalian cells, directs the expression of autofluorescent proteins that are localized to specific subcellular compartments and organelles via a signal peptide or protein fusions. The protein associated with autofluorescence is an endoplasmic reticulum (ER) signal sequence of calreticulin and KDEL (ER retention signal) fused to TagRFP (Red fluorescent protein).

A549 lung cells were seeded at a density of $1 \times 10^{5}$ cells/ml, in glass bottom Petri dishes (MatTek Corporation, USA) in 10\% FBS supplemented RPMI media and were incubated at $37{ }^{\circ} \mathrm{C}$ in $5 \% \mathrm{CO}_{2}$ for $4 \mathrm{hrs}$ for cell attachment before exposure to nanopolystyrene particles of concentration $1 \times 10^{12}$ particles per ml. Following the exposure period, the cells were washed twice with pre-warmed PBS $\left(37^{\circ} \mathrm{C}\right)$. A pre determined amount of CellLight ${ }^{\circledR}$ transduction solution was administered evenly to the Petri dishes. Cells were then incubated at $37{ }^{\circ} \mathrm{C}$ in $5 \% \mathrm{CO}_{2}$ for 24 hrs. The appropriate volume of CellLight ${ }^{\circledR}$ 
reagent for the number of cells exposed was calculated according to the manufacture's guidelines.

Intracellular localisation of polystyrene nanoparticles was visualized at room temperature under the laser scanning confocal microscope (LSM 510 Meta, Carl Zeiss Inc.) equipped with Argon (488 nm) and HeNe (543 nm) lasers. Images were acquired by multitracking (505-530 nm band pass filter to collect nanoparticles fluorescence and $560 \mathrm{~nm}$ long pass

filter for the cell organelle kit fluorescence) to avoid bleed through between the fluorophores, and the statistical analysis was carried out using the LSM 510 software.

\subsection{Raman spectroscopic measurements}

A Horiba Jobin-Yvon LabRAM HR800 spectrometer with an external 300 mW 785 nm diode laser as source was used throughout this work. For all measurements, a x100 immersion objective (LUMPlanF1, Olympus) was employed to reduce the spectral background. ${ }^{37}$ The confocal hole was set at $100 \mu \mathrm{m}$ for all measurements, the specified setting for confocal operation. The system was pre-calibrated to the $520.7 \mathrm{~cm}^{-1}$ spectral line of silicon. The Labram system is a confocal spectrometer that contains two interchangeable gratings (300 and 900 lines/mm respectively). In the following experiments, the 300 lines/mm grating was used, which gave a spectral dispersion of around $\sim 1.5 \mathrm{~cm}^{-1}$ per pixel. The detector used was a 16-bit dynamic range Peltier cooled CCD detector. Images of the sample were acquired using a video camera within the system.

For Raman mapping, an area corresponding to the map to be acquired was defined around the cells on the optical image provided by the instrument video camera. The step 
between two successive measurements was set to $1.5 \mu \mathrm{m}$ or $0.75 \mu \mathrm{m}^{38}$ and the backscattered Raman signal was integrated for 10 seconds over the spectral ranges from 400 to $1800 \mathrm{~cm}^{-1}$ and accumulated twice to enable an automatic software elimination of any spurious peaks.

\subsection{Data Analysis}

The different data analysis steps were performed using Matlab (Mathworks, USA). Before statistical analysis, a Savitsky-Golay filter ( $5^{\text {th }}$ order, 7 points) was applied to smooth the spectra and the reference spectrum constituting the background signal was subtracted.

K-means clustering analysis was utilised for initial analysis of the spectral maps. It is one of the simplest unsupervised learning algorithms used for spectral image analysis. It groups the spectra according to their similarity, forming clusters, each one representing regions of the image with identical molecular properties. ${ }^{39}$ The distribution of chemical similarity can then be visualised across the sample image. The number of clusters (k) has to be determined a priori by the operator before initiation of the classification of the data set. $\mathrm{K}$ centroids are defined, ideally as far as possible from each other, and then each point belonging to a data set is associated to the nearest centroid. When all the points have been associated with a centroid, the initial grouping is done. The second step consists of the calculation of new centroids as barycentres of the clusters resulting from the previous step. A new grouping is implemented based on the same data points and the new centroids. These operations are repeated until convergence is reached and there is no further movement of the centroids. Finally, k clusters are determined, each containing the 
most similar spectra from the image. From here, colours can be attributed to each cluster and false colours maps can be constructed to visualise the organisation of the clusters in the original image.

As K-means cluster analysis groups and represents similar spectra by their mean, Principal component analysis (PCA) was employed to further analyse the grouped spectra. PCA is a method of multivariate analysis broadly used with datasets of multiple

dimensions ${ }^{40}$. It allows the reduction of the number of variables in a multidimensional dataset, although it retains most of the variation within the dataset. The order of the PCs denotes their importance to the dataset. $\mathrm{PC}_{1}$ describes the highest amount of variation, $\mathrm{PC}_{2}$ the second greatest and so on. Therefore, var $\left(\mathrm{PC}_{1}\right) \geq \operatorname{var}\left(\mathrm{PC}_{2}\right) \geq \operatorname{var}\left(\mathrm{PC}_{\mathrm{p}}\right)$, where $\operatorname{var}\left(\mathrm{PC}_{\mathrm{i}}\right)$ represents the variance of $\mathrm{PC}_{\mathrm{i}}$ in the considered data set. Generally, the 3 first components represent more than $90 \%$ of the variance. This statistical method was preferred for this study to highlight the variability existing in the spectral data set recording during the different experiments. The other advantage of this method is the derivation of loadings which represent the variance for each variable (wavenumber) for a given PC. Analysis of the loadings of a PC can give information about the source of the variability inside a data set, derived from variations in the chemical components contributing to the spectra.

\section{Results and discussion}

\subsection{Particle Characterisation}


Full details of the results of the physico-chemical characterisation of the nanoparticle samples are provided in the Supplementary Information (S.1). In summary, the sizes of the nominally $50 \mathrm{~nm}$ and $100 \mathrm{~nm}$ nanoparticle samples were found to be somewhat dependent on the suspension medium and temperature, and the zeta potentials similarly varied, potentially consistent with interactions of the nanoparticle surface with the molecular components of the cell culture medium. ${ }^{2}$ Despite the variation in the exact nanoparticle sizes, for the purpose of brevity, the nanoparticles will be referred to as 50nm and 100nm particles throughout the manuscript.

\subsection{Cytotoxicity of particles.}

For all assays employed, at all timepoints, no significant cytotoxicity was observed over the concentration range employed for both 50 and $100 \mathrm{~nm}$ polystyrene nanoparticles (see Supplementary Information S.2). The observations are consistent with previous reports of exposure to neutral nanoparticles ${ }^{41}$ and indicate that the labelling of the nanoparticles with the fluorescent moiety does not impact significantly on the toxic response.

\subsection{Confocal Fluorescence Microscopy}

Figure 1 shows a confocal fluorescence and white light microscopic image of A549 cells after exposure to $50 \mathrm{~nm}$ fluorescently labelled polystyrene nanoparticles for a time of 24 hrs at a dose of $1 \times 10^{12}$ particles per ml of media. The images are typical of a range of doses and timepoints for both nanoparticle sizes. The fluorescence is observed to be spatially diffuse throughout the subcellular environment, and no specific subcellular localization of nanoparticles is inferred. 
The observations are not consistent with the increasingly accepted mechanisms of particle uptake by endocytosis and trafficking of nanoparticles through endosomes to lysosomes. $^{14,42}$ Such a diffuse distribution of fluorescence in cells exposed to labelled nanoparticles has recently been reported, however, and the phenomenon has been attributed to the uptake of labile fluorescent moieties, which become detached from the nanoparticles in the culture medium and are internalized in the cellular environment by passive molecular diffusion. Thus, the spatial distribution of the fluorescence profile does not reflect the subcellular ${ }^{9}$ distribution of the nanoparticles in the cells. The work of Salvati et al. ${ }^{9}$ highlights the importance of a complete screening of the nanoparticles employed for such studies in order to confirm the stability of the labeled nanoparticle and thus the validity of such fluorescent imaging procedures. For the purpose of this work, however, the observations of figure 1 highlight the importance of an independent technique to verify and profile the spatial distribution of nanoparticles in cells. Fluorescence microscopy identifies the distribution of the label, but notably is not chemically specific, and so is ineffective in independently and unambiguously locating the distribution of polystyrene.

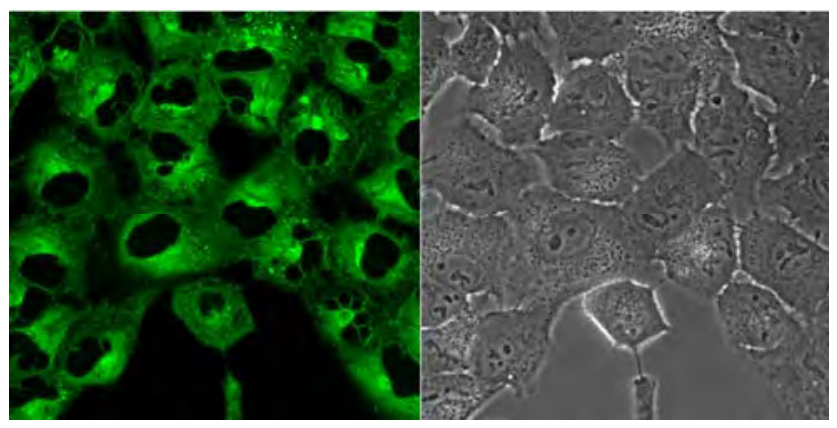

Figure 1: A549 cells exposed to $50 \mathrm{~nm}$ polystyrene nanoparticles x20 magnification after 24 hour exposure. 


\subsection{Raman Spectroscopy}

The literature contains many examples of works based on cell analysis using Raman spectroscopy ${ }^{43-46}$. In general, however, many problems arise due to substrate contributions, spectral background and poor signal to noise. Sampling in a confocal mode can minimize contributes due to substrates, and the use of substrates, such as $\mathrm{CaF}_{2}$, which have minimal contribution to the Raman spectra in the region of interest, improves matters further. In tissue samples, it has been demonstrated that working in immersion significantly reduces the spectral background ${ }^{37}$, and for the case of cell cultures on collagen gels, measured in immersion, the background has been shown to be reduced to that of the surrounding water ${ }^{47}$.

Although progress has been made in the measurement techniques, little attention has been paid to the quality of the cellular samples. The aim of this work is to detect and localize nanoparticles within the cytoplasm of the cells without the use of a specific label. In order to achieve this goal, it is crucial to first optimise the sample preparation techniques to reduce as much as possible variations related to the cell handling. A full description of the optimization of the cell culturing and fixation process is provided in the Supplementary Information (S.3).

As the fixation process was shown to have negligible effect on the Raman spectra, A549 cells exposed to $100 \mathrm{~nm}$ polystyrene nanoparticles at a concentration of $1 \times 10^{12}$ nanoparticles per $\mathrm{ml}$ of media for a period of $24 \mathrm{hrs}$ were formalin fixed in $\mathrm{CaF}_{2}$ substrates and were mapped for their Raman spectral profile. 
The two main factors influencing the time needed to map a full cell are the step size and the acquisition time. Using a $785 \mathrm{~nm}$ laser as source, a $10 \mathrm{~s}$ acquisition gives a signal to noise ratio more than acceptable for the identification of the different spectral features present. ${ }^{22,} 38$ However, two accumulations are required by the software to remove any spurious spikes in the spectra recorded, and thus the total acquisition time per spectrum was $20 \mathrm{~s}(2 \times 10 \mathrm{~s})$. A mild smoothing was applied to further improve the spectral quality, as described in Section 2.8. The instrument software allows the selection of customised areas for mapping, as presented in figure $2 \mathrm{~A}$, considerably reducing the measurement time, and a step size of $1.5 \mu \mathrm{m}$ has been used in order not to exceed $\sim 4$ hrs per cell, a timescale which is most feasible for maintaining sample integrity and stable conditions for spectral mapping. After completion of the spectral recording, the map was exported to Matlab for analysis using K-means clustering. For cells exposed to nanopolysterene, it is expected that the K-means clustering will be able to localise the nanoparticles within the cellular environment.

Using a 100x objective, the visible image obtained from the cells is rather detailed (Figure 2A). The nucleus is clearly identifiable and the nucleoli can also be seen. The membrane of the cells is well defined and the cytoplasm presents different structures and the region containing the endoplasmic reticulum can be easily recognised. Figure 2B presents the results obtained using 10 different groups for the K-means cluster analysis. Increasing the number of groups to 10 allows consideration of the variability existing in the spectra recorded from the edge of the cells which have a lower intensity and therefore a weaker signal to noise ratio. A cluster has been formed corresponding to the nuclear 
area (cluster 1) but the analysis does not discriminate between the nucleus and nucleoli.

Similarly, distinct clusters are assigned to the cytoplasm and membrane.
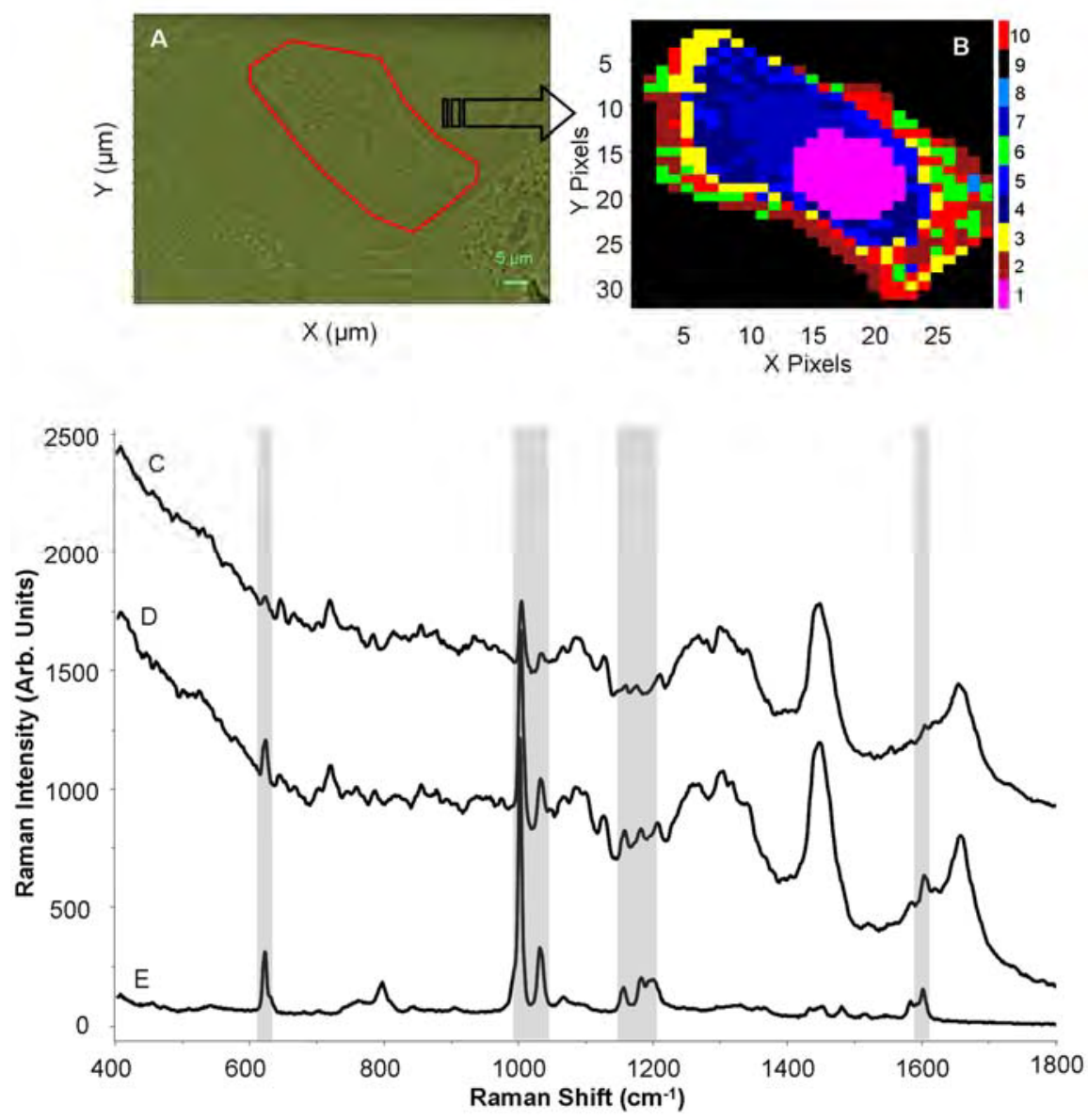

Figure 2: Top; (A) Microscopic image of an A549 cell, showing the area identified for spectral mapping. (B) K-means cluster map of the Raman profile of the same cell. Bottom; Raman spectra of (C) cytoplasm, (D) cytoplasm showing the contribution of spectral features of (F) polystyrene nanoparticles. Grey shading is a guide to identification of characteristic Raman features of polystyrene. Spectra are offset for clarity

Notably, however, none of the 10 clusters identified by the analysis exhibits clear signatures which can be associated with polystyrene (figure 2 bottom). It is expected that the nanoparticles will be predominantly localised within the cytoplasmic region, but there is no evidence of specific polystyrene peaks in the spectrum of the cytoplasm (Figure 
2C). Although it overlaps with the strong and sharp phenyl group of aromatic amino acids in cells, the best indicator of the presence of nanopolysterene in the spectra recorded remains the intensity of the strong $1004 \mathrm{~cm}^{-1}$ peak. Based on this observation, it has been possible to manually screen the map and identify the presence of these features in individual Raman spectra (figure 2D). The manually identified polystyrene spectra are, however, sparsely located throughout the cell, a strong indication that the fluorescence map of figure 1 is not representative of the distribution of polystyrene nanoparticles within the cell. Although Raman spectroscopy can detect the presence of nanoparticles in the cells, the K-means clustering analysis does not group their signature as a spatially defined cluster.

The use of a 100x objective provides maximum lateral resolution and helps to obtain visible images which detail the cell morphology. However, the focal depth is minimised and, in an automated map, it is difficult to optimise acquisition conditions over the spatial extent of the cell. The visible image in figure 2A highlights this phenomenon, as, although the focus is optimised for the nucleus, the edge of the cell remains blurry. This difference is enough to create a loss in the Raman intensity when recording spectra on the outer parts of the cells, reducing considerably the signal to noise ratio. For this reason, the area selected for spectral mapping was reduced, as indicated in figure 3 IA. Moreover, scanning a smaller area allows a decrease of the lateral step size to $0.75 \mu \mathrm{m}$ without increasing the overall acquisition time. Thus, the definition of the map recorded is improved and a more precise localisation of the nanopolysterene can be achieved. 
l)

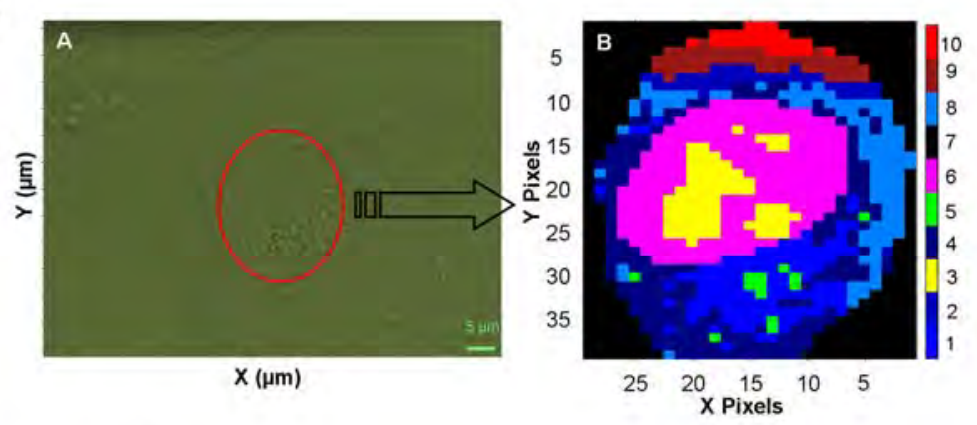

II)

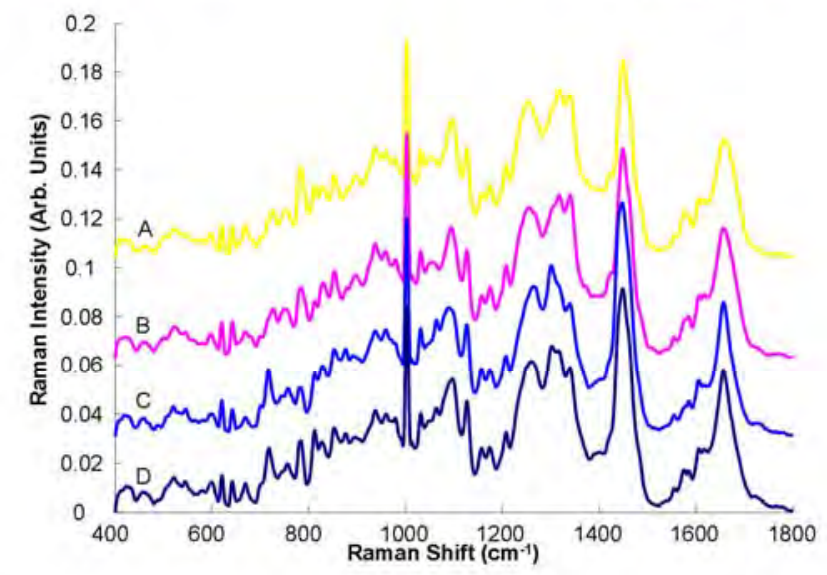

III)

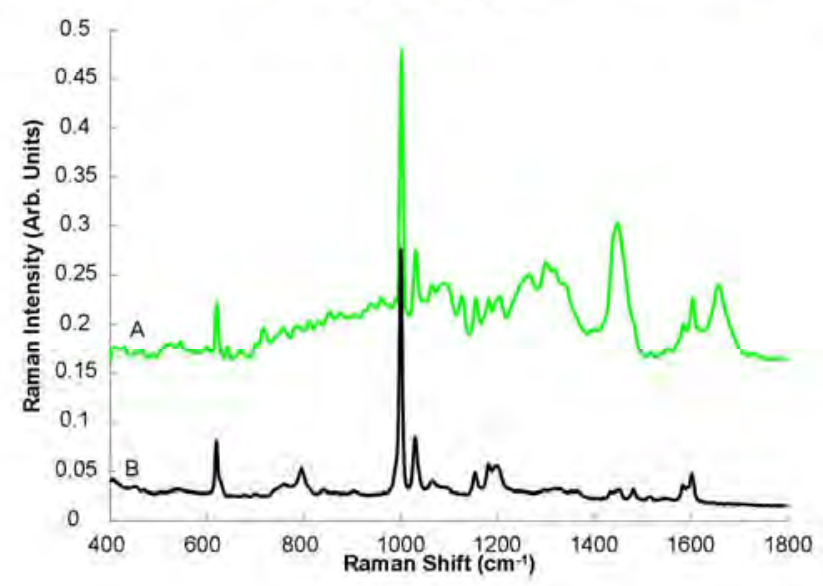

Figure 3: I; (A) Microscopic image of an A549 cell, showing the reduced area identified for spectral mapping. (B) K-means cluster map of the Raman profile of the same reduced area. II; K-means spectra of clusters 3 (A - representing nucleoli), 6 (B - representing nucleus), 1 and 4 (C and D, both from the cytoplasm). Spectra are offset for clarity. III; K-means spectrum of Cluster 5 (A), compared to the Raman spectrum polystyrene nanoparticles (B). Spectra are offset for clarity 
Under these conditions, the K-means clustering analysis run using 10 groups yields more specific clusters, as shown in figure 3 IB. The nucleoli spectra form a specific group (cluster 3), distinct from the nucleus (cluster 6). The corresponding mean spectra are displayed in figure 3 II. The cytoplasm is represented by a number of different clusters $(1,2,4,8,9,10)$. Notably, nanopolysterene can now be localised in the cytoplasm according to cluster 5 , the corresponding mean spectrum of which is presented in figure 3 IIIA. Although some cellular features clearly contribute to the cluster spectrum, it is dominated by specific features originating from polystyrene. Notably, in comparison to figure 1, figure 3 IB gives a map of the distribution of the fingerprint of the molecular structure of polystyrene, rather than the fluorescent label.

K-means cluster analysis yields the average spectra for the identified clusters. These average spectra can contain contributions from points on the boundaries between the cellular regions and a direct comparison does not always easily facilitate identification of the differences in the biochemical composition. Cluster 5 clearly identifies the presence of polystyrene nanoparticles localised in the cytoplasm, but the averaged spectrum also exhibits clear contributions of the biological environment. PCA can be employed to highlight the biochemical differences between the subcellular regions. ${ }^{48}$ In figure 3 IB, cluster 5 is predominantly surrounded by cytoplasmic regions grouped within cluster 1. 

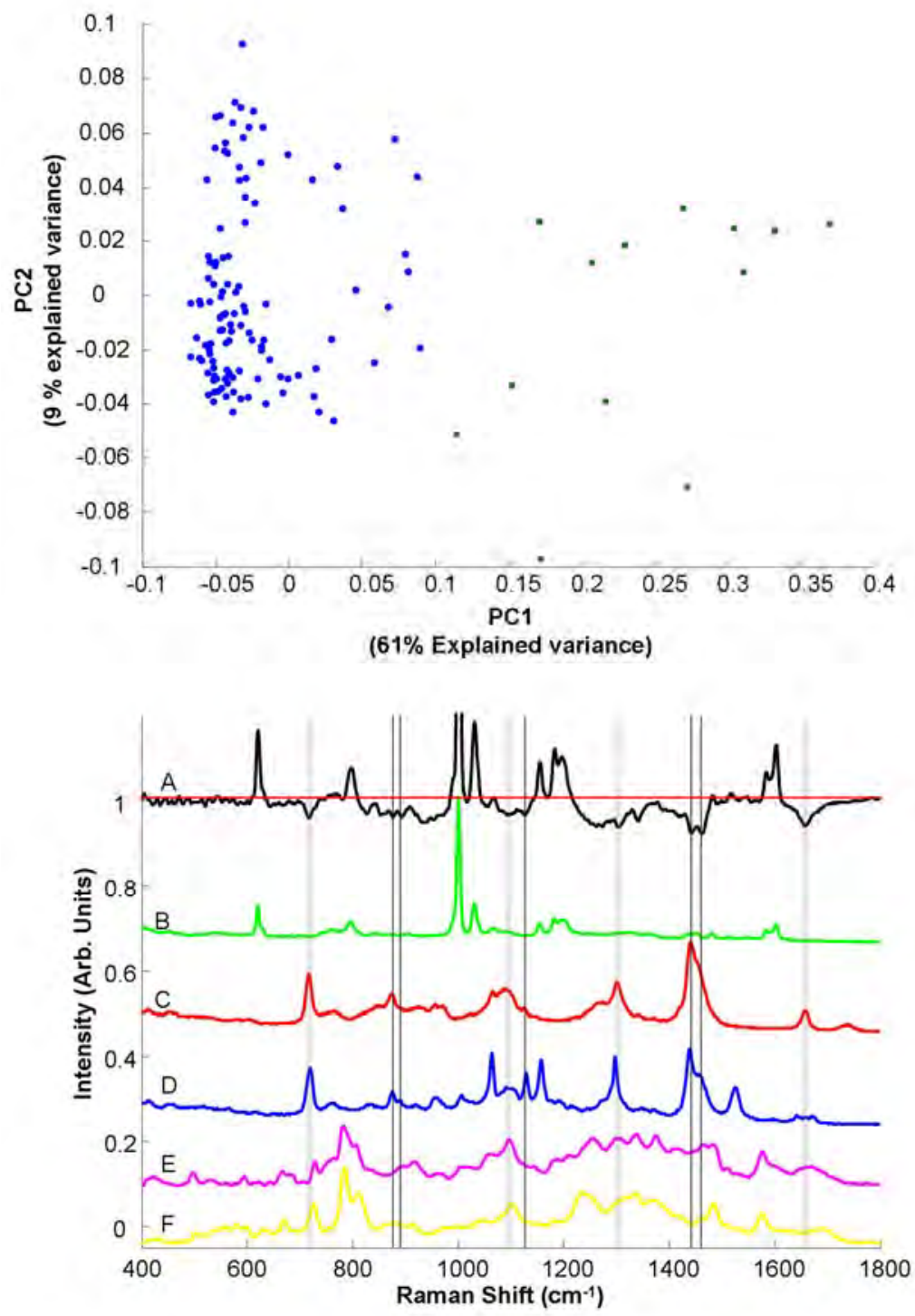

Figure 4: Top; Scatter plot of the PCA of spectra associated with clusters 1 (Blue) and 5 (Green). Bottom; (A) Loading of PC1 (B) Raman Spectrum of polystyrene nanoparticles (C) of L- $\alpha$-Phosphatidylcholine, (D) of Sphingomyelin, (E) of DNA and (F) of RNA.

Figure 4 (top) is a scatter plot of the PCA of spectra associated with K-means clusters 1 and 5. For visualisation purposes, spectra associated with cluster 1 are coloured blue, while those from cluster 5 are coloured green, and although the data is rather dispersed, some differentiation between the two clusters according to PC1 is apparent. PC1 accounts 
for $61 \%$ of the variance and, as shown in the loadings plot of figure 4 (bottom), it is dominated by positive contributions of polystyrene (figure 4 B). Notably, the negative contributions of PC1 match well with the Raman features of lipids such as L- $\alpha$ Phosphatidylcholine (figure 4 C) and also sphingomyelin (figure 4 D). For comparison, the Raman spectra of DNA (figure 4 E) and RNA (figure 4 F) are also shown, and it is clear that they exhibit few or no similarities with PC1. High loadings of PC1 for cluster 5 are therefore an indication of the dominance of polystyrene. Positive loadings of PC1 for some of Cluster 1 may indicate regions of overlap between the localised nanoparticles and the surrounding cytoplasm, which, although they have significant polystyrene contributions, are represented in the K-means cluster analysis by the average spectrum of cluster 1.

An established mechanism for the transport of nanoparticles in cells is via endosomes and later lysosomes. ${ }^{42}$ A number of studies have also demonstrated that, in the later stages of trafficking, individually endocytosed nanoparticles accumulate in larger multivescular bodies ${ }^{33}$ and they have also been seen to be localized in the endoplasmic reticulum and Gogli apparatus. ${ }^{49}$ Notably, in figure 3 IA, the majority of the nanoparticles, identified in green as cluster 5 , are surrounded by cytoplasmic regions of cluster 1 , which is relatively spatially extensive, particularly compared to typical sizes of lysosomes $(1-2 \mu \mathrm{m})$. In the white light image of figure 3 IB, this region can be identified as the ER, which may be expected to be rich in lipidic compounds, and a PCA of the different regions of the cytoplasm, as shown in the scatter plot of figure 5 (top) and the corresponding loadings of figure 5 (bottom), confirms this. Cluster 4, on the other hand is relatively rich in nucleic acids, which may be due to the presence of mitochondria. 

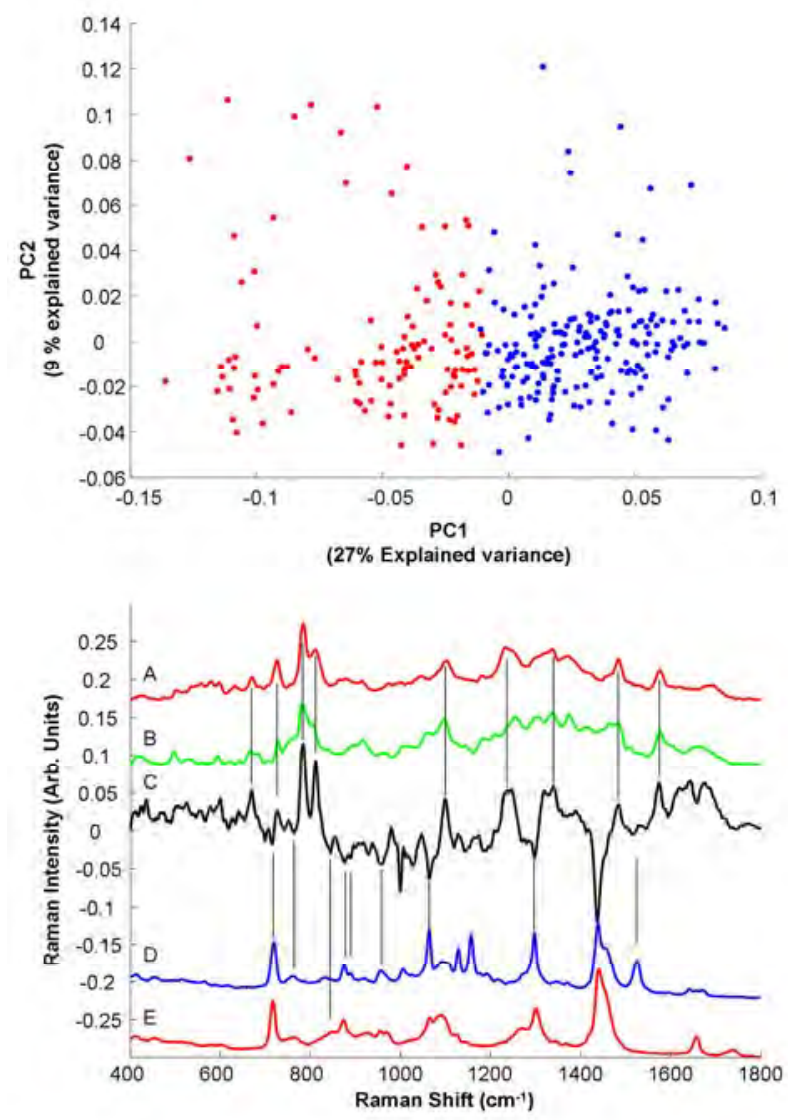

Figure 5: Top; Scatter plot of the PCA of spectra associated with clusters 1 (red) and 4 (blue). Bottom; (A) Raman Spectrum of RNA (B) Raman Spectrum of DNA (C) Loading of PC1, (D) Raman spectrum of Sphingomyelin, (E) Raman spectrum of L- $\alpha$-Phosphatidylcholine.

Figure 6 shows an image of A549 cells exposed for 24 hrs to $50 \mathrm{~nm}$ fluorescently labelled polystyrene nanoparticles, also stained for ER, as described in section 2.6. Although, as outlined in relation to Figure 1, the fluorescence distribution is diffuse and therefore not exclusively attributable to the presence of nanoparticles within the cell, the confocal image indicates a strong correlation between the ER stain and the fluorescence of the nanoparticle label, and any locally concentrated fluorescence which may be indicative of encapsulated nanoparticles is contained within the ER, clearly visible in the white light 
image of figure $6 \mathrm{~B}$. The analysis supports the attribution of the subcellular environment of K-means cluster 1 as endoplasmic reticulum.

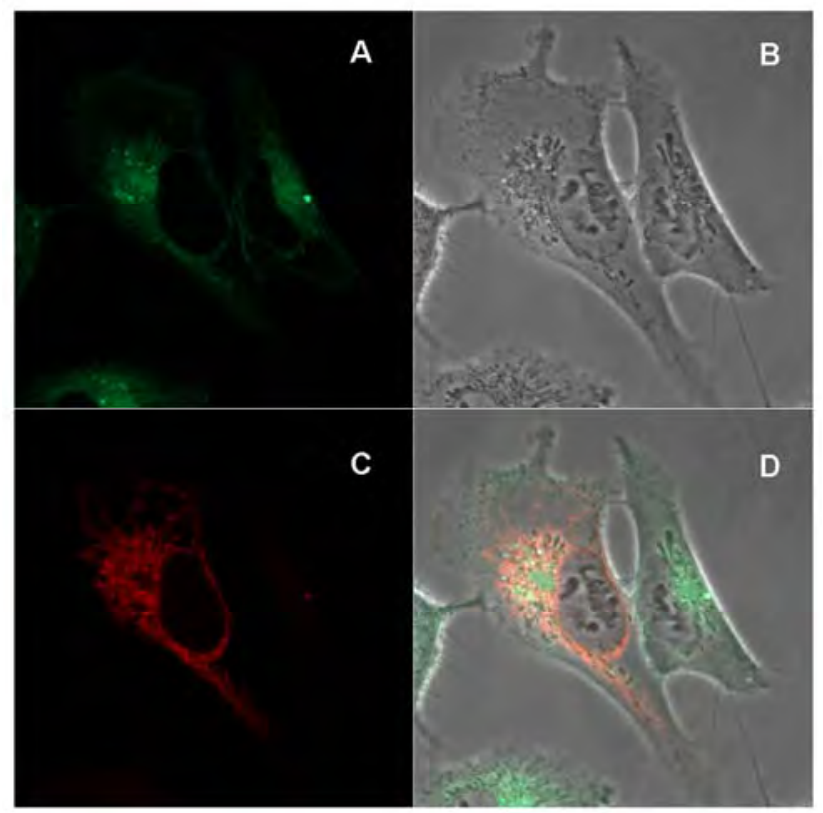

Figure 6: Confocal microscopic images obtained of $50 \mathrm{~nm}$ polystyrene nanoparticles within A549 cells that have also been treated with CellLight ${ }^{\circledR}$ Endoplasmic Reticulum staining kit. (A) Confocal image showing the fluorescence of the particles only, using the 505-530 nm band pass filter. (B) Optical image of the cell showing no fluorescence. (C) Confocal image of the fluorescent endoplasmic reticulum of the cell following transduction with the CellLight ${ }^{\circledR}$ kit using the $560 \mathrm{~nm}$ long pass filter and (D) Image of fluorescence overlap of both the $50 \mathrm{~nm}$ particles and the fluorescently transduced ER. The fluorescence overlap is shown in a yellow-orange colour.

\section{Discussion}

The work presented here represents an initial proof of concept, to demonstrate the potential use of Raman spectroscopy to identify and locate nanoparticles in cells and to probe their subcellular environment. No attempt has, as yet, been made to quantify the amount of nanoparticles located or the sensitivity and detection limit of the technique. 
Instrumentally, the spatial resolution can be improved by moving to lower wavelength sources, although the excitation of any fluorescence from the nanoparticles and the cell constituents should be avoided. However, as it scales linearly with wavelength, a move from $785 \mathrm{~nm}$ to $473 \mathrm{~nm}$ should result in an improvement in lateral resolution by a factor of 1 1.7. Ultimately, the confocal mode of operation can provide 3D localisation of the nanoparticles at submicron resolution.

Fixed cells were employed in this work to facilitate prolonged mapping. However, the technique can be applied to live cells ${ }^{38}$, and the identification of a characteristic spectral marker for the nanoparticles or a cell metabolite could ultimately facilitate real time monitoring. The subcellular environment of the cell is complex, and differentiation of the subcellular environments based on characteristic Raman spectra is best facilitated using multivariate statistics, two examples of which are illustrated here. A range of other data mining techniques are available, however, which could improve the molecular sensitivity of the technique.

It is notable that the initial attempts to locate the nanoparticles within the cell, using a 1.5 $\mu \mathrm{m}$ step size over the whole cell area proved inconclusive. The mapping conditions also failed to identify the nucleoli within the nucleus, however. In the automated mapping protocol, no adjustment of the focussing conditions was performed, and, using the x100 objective in a confocal geometry, the focussing conditions, optimised in the region of the nucleus, are less well optimised over the extent of the whole cell. Therefore, the variability of spectra from the outer part of the cell is significantly higher than the variability which should differentiate the spectra containing polysterene from those containing only cellular features. An increase of the number of clusters resulted only in 
the creation of more clusters in the membrane region of the cells. Restricting the mapping to the centre part of the cells provides a more consistent signal without adjustment of the focus. In this case, both K-means clustering and PCA differentiate regions with clear contributions of polystyrene to the spectra. Improved automated mapping protocols which include auto-focusing could improve the routine application of the technique.

Polystyrene nanoparticles are emerging as potential standards for nanotoxicity, notably in their aminated form. The aromatic styrene unit is a relatively strong Raman scatterer, and thus they are particularly suitable for Raman mapping. The example of fluorescently labelled nanoparticles which potentially lose the label, with the result that fluorescence microscopy does not unambiguously identify the nanoparticles within the cells, highlights the potential of the technique as a label free probe applicable to a broad range of nanoparticles. To demonstrate the universality of the technique, the study will be extended in the future to a broader range of both organic and inorganic nanoparticles.

\section{Conclusion}

This study demonstrates the ability of Raman microspectroscopy to localise nanoparticles in the subcellular environment, based on their chemical structure. The measurements also indicate that the technique can be employed to identify the subcellular environment. Raman has previously been employed to monitor changes in the metabolism of cells, particularly due to external agents, and thus this label free, non invasive tool can potentially simultaneously, locate and identify nanoparticles, probe their local 
environment and ultimately changes to the metabolism of the cell due to cell-nanoparticle interactions.

\section{Acknowledgements}

This research was supported by the Integrated NanoScience Platform, Ireland, and the

National Biophotonics and Imaging Platform (NBIP) Ireland, both funded under the Higher Education Authority PRTLI (Programme for Research in Third Level Institutions)

Cycle 4, co-funded by the Irish Government and the European Union Structural fund. 


\section{References}

1. Berntsen P, Park CY, Rothen-Rutishauser B, Tsuda A, Sager TM, Molina RM, Donaghey TC, Alencar AM, Kasahara DI, Ericsson T, Millet EJ, Swenson J, Tschumperlin DJ, Butler JP, Brain JD, Fredberg JJ, Gehr P, Zhou EH, Journal of The Royal Society Interface, 2010, 7, S331S340.

2. Lundqvist M, Stigler J, Elia G, Lynch I, Cedervall T, Dawson KA, Proceedings of the National Academy of Sciences, 2008, 105, 14265-14270.

3. Clift MJD, Rothen-Rutishauser B, Brown DM, Duffin R, Donaldson K, Proudfoot L, Guy K, Stone V, Toxicology and Applied Pharmacology, 2008, 232, 418-427.

4. Rejman J, Oberle V, Zuhorn IS, Hoekstra D, Biochem. J., 2004, 377, 159-169.

5. Rothen-Rutishauser B, Muhlfeld C, Blank F, Musso C, Gehr P, Particle and Fibre Toxicology, 2007, 4, 9.

6. Naha PC, Bhattacharya K, Tenuta T, Dawson KA, Lynch I, Gracia A, Lyng FM, Byrne HJ, Toxicology Letters, 2010, 198, 134-143.

7. Roy I, Ohulchanskyy TY, Bharali DJ, Pudavar HE, Mistretta RA, Kaur N, Prasad PN, Proceedings of the National Academy of Sciences of the United States of America, 2005, 102, 279-284.

8. $\quad$ Cang H, Xu CS, Montiel D, Yang H, Opt. Lett., 2007, 32, 2729-2731.

9. Salvati A, Aberg C, Dos Santos T, Varela J, Pinto P, Lynch I, Dawson KA, Nanomedicine, 2011, 7, 818-826.

10. Suh H, Jeong B, Liu F, Kim SW, Pharmaceutical Research, 1998, 15, 1495-1498.

11. Yin Win K, Feng S-S, Biomaterials, 2005, 26, 2713-2722.

12. Gajraj A, Ofoli RY, Langmuir, 2000, 16, 8085-8094.

13. Davoren M, Herzog E, Casey A, Cottineau B, Chambers G, Byrne HJ, Lyng FM, Toxicology in Vitro, 2007, 21, 438-448.

14. Shapero K, Fenaroli F, Lynch I, Cottell DC, Salvati A, Dawson KA, Molecular BioSystems, 2011, 7, 371-378.

15. Bouwmeester H, Lynch I, Marvin HJ, Dawson KA, Berges M, Braguer D, Byrne HJ, Casey A, Chambers G, Clift MJ, Elia G, Fernandes TF, Fjellsbo LB, Hatto P, Juillerat L, Klein C, Kreyling WG, Nickel C, Riediker M, Stone V, Nanotoxicology, 2011, 5, 1-11.

16. Hodges CM, Akhavan J, Spectrochimica Acta Part A: Molecular Spectroscopy, 1990, 46, 303-307.

17. Kneipp K, Kneipp H, Itzkan I, Dasari RR, Feld MS, Chemical Reviews, 1999, 99, 29572976.

18. Vankeirsbilck T, Vercauteren A, Baeyens W, Van der Weken G, Verpoort F, Vergote G, Remon JP, TrAC Trends in Analytical Chemistry, 2002, 21, 869-877.

19. Wilson AS, Edwards HGM, Farwell DW, Janaway RC, Journal of Raman Spectroscopy, 1999, 30, 367-373.

20. Lyng FM, Faoláin EÓ, Conroy J, Meade AD, Knief P, Duffy B, Hunter MB, Byrne JM, Kelehan P, Byrne HJ, Experimental and Molecular Pathology, 2007, 82, 121-129. 
21. Byrne HJ, Sockalingum GD, Stone N.in Biomedical Applications of Synchrotron Infrared Microspectroscopy: A Practical Approach, David M, RSC Analytical Spectroscopy Monographs 2011,11, 105-143

22. Draux F, Jeannesson P, Beljebbar A, Tfayli A, Fourre N, Manfait M, Sule-Suso J, Sockalingum GD, Analyst, 2009, 134, 542-548.

23. Mariani MM, Day PJ, Deckert V, Integr Biol (Camb), 2010, 2, 94-101.

24. Matthaus C, Chernenko T, Newmark JA, Warner CM, Diem M, Biophys J, 2007, 93, 668-673.

25. Meister K, Schmidt DA, Brundermann E, Havenith M, Analyst, 2010, 135, 1370-1374.

26. Notingher I, Hench LL, Expert Rev Med Devices, 2006, 3, 215-234.

27. Notingher I, Verrier S, Haque S, Polak JM, Hench LL, Biopolymers, 2003, 72, 230-240.

28. Yu C, Gestl E, Eckert K, Allara D, Irudayaraj J, Cancer Detect Prev, 2006, 30, 515-522.

29. Puppels GJ, de Mul FF, Otto C, Greve J, Robert-Nicoud M, Arndt-Jovin DJ, Jovin TM, Nature, 1990, 347, 301-303.

30. Puppels GJ, Garritsen HS, Segers-Nolten GM, de Mul FF, Greve J, Biophys J, 1991, 60, 1046-1056.

31. Knief P, Clarke C, Herzog E, Davoren M, Lyng FM, Meade AD, Byrne HJ, Analyst, 2009, 134, 1182-1191.

32. Kneipp K, Haka AS, Kneipp H, Badizadegan K, Yoshizawa N, Boone C, Shafer-Peltier KE, Motz JT, Dasari RR, Feld MS, Appl. Spectrosc., 2002, 56, 150-154.

33. Kneipp J, Kneipp H, McLaughlin M, Brown D, Kneipp K, Nano Letters, 2006, 6, 22252231.

34. Kneipp J, Kneipp H, Rajadurai A, Redmond RW, Kneipp K, Journal of Raman Spectroscopy, 2009, 40, 1-5.

35. Kneipp J, Kneipp H, Rice WL, Kneipp K, Analytical Chemistry, 2005, 77, 2381-2385.

36. Kneipp J, Kneipp H, Wittig B, Kneipp K, The Journal of Physical Chemistry C, 2010, 114, 7421-7426.

37. Bonnier F, Mehmood A, Knief P, Meade AD, Hornebeck W, Lambkin H, Flynn K, McDonagh V, Healy C, Lee TC, Lyng FM, Byrne HJ, Journal of Raman Spectroscopy, 2011, 42, 888-896.

38. Bonnier F, Knief P, Lim B, Meade AD, Dorney J, Bhattacharya K, Lyng FM, Byrne HJ, Analyst, 2010, 135, 3169-3177.

39. MacQueen JB.in Proceedings of 5-th Berkeley Symposium on Mathematical Statistics and Probability, Berkeley, University of California Press, 1967,1, 281-297

40. Varmuza K. 2009. Introduction to multivariate statistical analysis in chemometrics. New york: CRC Press.

41. Ryman-Rasmussen JP, Riviere JE, Monteiro-Riviere NA, J Invest Dermatol, 2006, 127, 143-153.

42. Nel AE, Madler L, Velegol D, Xia T, Hoek EMV, Somasundaran P, Klaessig F, Castranova V, Thompson M, Nat Mater, 2009, 8, 543-557.

43. Draux F, Gobinet C, Sule-Suso J, Trussardi A, Manfait M, Jeannesson P, Sockalingum GD, Anal Bioanal Chem, 2010, 397, 2727-2737.

44. Mariani MM, Lampen P, Popp J, Wood BR, Deckert V, Analyst, 2009, 134, 1154-1161.

45. Miljkovic M, Chernenko T, Romeo MJ, Bird B, Matthaus C, Diem M, Analyst, 2010, 135, 2002-2013. 
46. Nawaz H, Bonnier F, Knief P, Howe O, Lyng FM, Meade AD, Byrne HJ, Analyst, 2010, 135, 3070-3076.

47. Bonnier F, Meade AD, Merzha S, Knief P, Bhattacharya K, Lyng FM, Byrne HJ, Analyst, 2010, 135, 1697-1703.

48. Bonnier F, Byrne HJ, Analyst, 2012, 137, 322-332.

49. Chang MY, Shiau AL, Chen YH, Chang CJ, Chen HH, Wu CL, Cancer Sci, 2008, 99, 1479-1484. 
Identifying and localizing intracellular nanoparticles using Raman Spectroscopy:

Jennifer Dorney ${ }^{1,2}$, Franck Bonnier ${ }^{3 *}$, Amaya Garcia ${ }^{3}$, Alan Casey ${ }^{1}$, Gordon Chambers ${ }^{1,2}$, Hugh J. Byrne ${ }^{1}$

1. Nanolab Research Centre, Focas Research Institute, Dublin Institute of Technology (DIT), Camden Row, Dublin 8, Ireland

2. School of Physics, Dublin Institute of Technology (DIT), Kevin Street, Dublin 8, Ireland

3. Radiation and Environmental Science Centre, Dublin Institute of Technology (DIT), Camden Row, Dublin 8, Ireland

\section{Supplementary Information}

\section{S.1 Physico Chemical Characterisation of the Nanoparticles}

Physico-chemical characterization of the particles was performed by dynamic light scattering using a Malvern Zetasizer ZS. A HeNe laser with a wavelength of 633nm and an avalanche photodiode detector, Q.E. $>50 \%$ at $633 \mathrm{~nm}$ at $173^{\circ}$ (backscatter detection) was used. Particle size measurements and zeta potential measurements were carried out in the respective biological media at a concentration of $1 \times 10^{12}$ particles per $\mathrm{ml}$ at $37^{\circ} \mathrm{C}$. The number of particles per ml of suspension may be determined from the following equation, as specified by the supplier:

$$
\text { Number of particles/ml }=\frac{6 \mathrm{C} \times 10^{12}}{\rho \times \pi \times \Phi}
$$

where: $\mathrm{C}=$ Concentration of suspended beads in $\mathrm{g} / \mathrm{ml}$

$\rho=$ Density of polymer in $\mathrm{g} / \mathrm{ml}$

$\Phi=$ Diameter of suspended particles in $\mu \mathrm{m}$. 
The size and zeta potential of both the nominally $50 \mathrm{~nm}$ and $100 \mathrm{~nm}$ sized particles differed slightly according to the medium in which they were suspended, when measured by dynamic light scattering. Nominally $50 \mathrm{~nm}$ particles were found to have an average particle size in $\mathrm{H}_{2} \mathrm{O}$ at $25^{\circ} \mathrm{C}$ and $37^{\circ} \mathrm{C}$ of $52 \mathrm{~nm}$ and $53 \mathrm{~nm}$, respectively, while $50 \mathrm{~nm}$ particles in $10 \%$ FBS RPMI media at $25^{\circ} \mathrm{C}$ and $37^{\circ} \mathrm{C}$ were determined to have particle sizes of $49 \mathrm{~nm}$ and $38 \mathrm{~nm}$ respectively. The average particle sizes for the $100 \mathrm{~nm}$ samples in $\mathrm{H}_{2} \mathrm{O}$ at $25^{\circ} \mathrm{C}$ and $37^{\circ} \mathrm{C}$ were found to be $169 \mathrm{~nm}$ and $138 \mathrm{~nm}$ respectively, while average particle sizes for $100 \mathrm{~nm}$ samples measured in medium at $25^{\circ} \mathrm{C}$ and $37^{\circ} \mathrm{C}$ were found to be $149 \mathrm{~nm}$ and $116 \mathrm{~nm}$ respectively. Zeta potential measurements of the 50nm samples revealed that particles dispersed in $\mathrm{H}_{2} \mathrm{O}$ at $25^{\circ} \mathrm{C}$ and $37^{\circ} \mathrm{C}$ were found to be -62 $\mathrm{mV}$ and $-53 \mathrm{mV}$ respectively, and in media at $25^{\circ} \mathrm{C}$ and $37^{\circ} \mathrm{C}$ to be $-13 \mathrm{mV}$ and $-12 \mathrm{mV}$ indicating that the solution was moderately stable at the temperatures measured. $100 \mathrm{~nm}$ particles were found to have zeta potential values, in $\mathrm{H}_{2} \mathrm{O}$ at $25^{\circ} \mathrm{C}$ and $37^{\circ} \mathrm{C}$, of -18.62 $\mathrm{mV}$ and $-15.09 \mathrm{mV}$ respectively. Similarly, zeta potential measurements of $100 \mathrm{~nm}$ particles in $\mathrm{H}_{2} \mathrm{O}$ at $25^{\circ} \mathrm{C}$ and $37^{\circ} \mathrm{C}$ were found to have values of $-42.32 \mathrm{mV}$ and -38.27 $\mathrm{mV}$ respectively, also indicating the solution was moderately stable at both temperatures. Changes in zeta potential between $\mathrm{H}_{2} \mathrm{O}$ and cell culture medium are well documented and are proposed to result from the interaction of the nanoparticle surface with the molecular components of the cell culture medium ${ }^{1}$. Despite the uncertainty in the exact nanoparticle sizes, for the purpose of brevity, the nanoparticles will be referred to as 50nm and 100nm particles throughout the manuscript. 


\section{S.2 Cytotoxicity assays}

The cytotoxicity assays employed during this experiment were Alamar Blue ${ }^{\mathrm{TM}}(\mathrm{AB})$, Neutral Red (NR), Coomassie Blue (CB) and 3-(4,5-dimethylthiazol-2-yl)-2,5diphenyltetrazolium bromide (MTT). For cytotoxicity evaluation, cells were seeded in 96-well micro plates (Nunc, Denmark) in triplicate for each of the four time points studied 24, 48, 72, $96 \mathrm{hr}$. Plates were seeded at a density of $1.5 \times 10^{5}$ cells/ml for $24 \mathrm{hr}, 5$ x $10^{4}$ cells/ml for $48 \mathrm{hr}, 3 \times 10^{4}$ cells/ml for $72 \mathrm{hr}$ and $2 \times 10^{4}$ cells/ml for $96 \mathrm{hr}$ exposure. These densities were found to be optimal to achieve the desired confluence at the end of the exposure period. After an initial $24 \mathrm{hr}$ of cell attachment, the media was removed and the plates were washed with $100 \mu \mathrm{l} /$ well phosphate buffered saline (PBS). Cells were then treated with increasing concentrations of each nanomaterial and with a positive control of a 10\% DMSO 90\% media solution. The cells were then incubated for the desired time period and the cytotoxic effects evaluated. For each independent experiment, six replicate wells were used for control, six replicate wells were employed for the positive control and six replicate wells were used for each test concentration per micro plate. For cytotoxicity evaluation, fluorescence and absorbance were all quantified using a microplate reader (TECAN GENios, Grodig, Austria). Further details for each of the assays performed can be found in ${ }^{2}$.

For all assays employed, at all timepoints, no significant cytotoxicity was observed over the concentration range employed for both 50 and $100 \mathrm{~nm}$ polystyrene nanoparticles. As an example, Figure S.1 shows the MTT response to exposure of $50 \mathrm{~nm}$ polystyrene nanoparticles. The observations are consistent with previous reports of exposure to 
neutral nanoparticles ${ }^{3}$ and indicate that the labelling of the nanoparticles with the fluorescent moiety does not impact significantly on the toxic response.

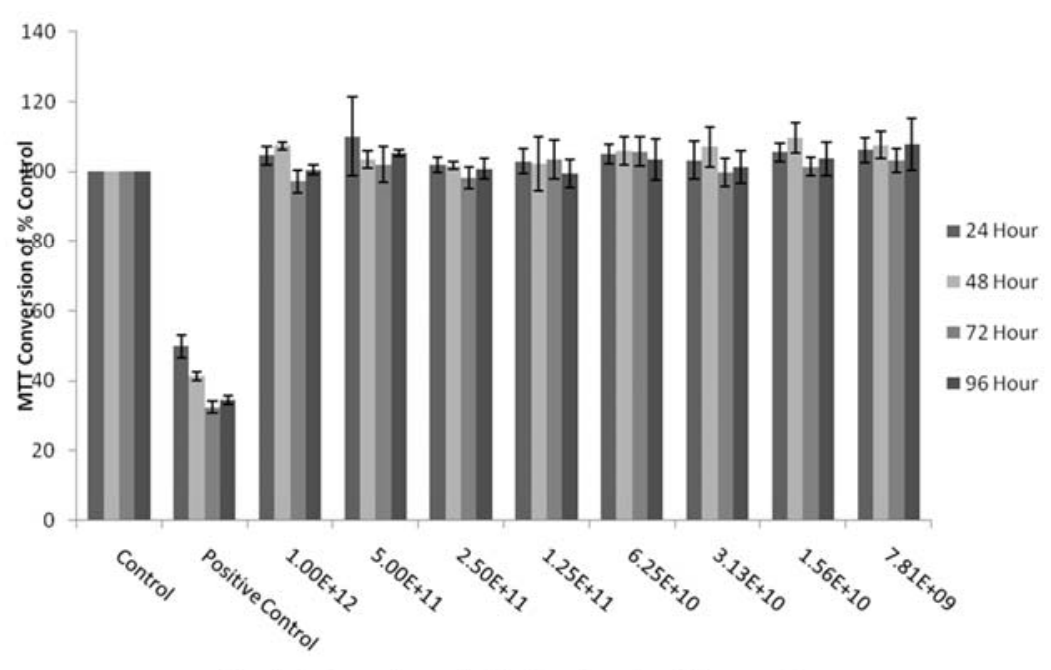

$50 \mathrm{~nm}$ Polystyrene Concentration / number of particles per $\mathrm{ml}$

Figure S.1: Cytotoxicity of $50 \mathrm{~nm}$ Duke Scientific Nanopolystyrene after 24, 48, 72 and 96 hour exposures determined by the MTT assay. Data are expressed as percent of control mean $\pm S D$ of three independent experiments.

\section{S.3 Sample preparation and cell morphology}

When working with A549 cells, the first observation made was the inconsistency of the cell morphology while preparing the samples. The cells were seeded on $\mathrm{CaF}_{2}$ substrates, left overnight in the incubator and used for Raman analysis the next day for both live cell and fixed cell analysis. The protocols used were standard, but still the cells could exhibit particular characteristics and "stressed" samples seemed to be regularly observed. The main characteristic of these cells was the presence of microscopic "droplets" $(\sim 1-5 \mu \mathrm{m})$ in the cytoplasm. Their number was seen to vary considerably from sample to sample and thus the ability to resolve different structures present in the cytoplasm varied 
significantly. This phenomenon is independent of the cell fixation using formalin as the features can be seen in both live cells (figure S2.A) and fixed cells (figure S2.B). The droplets are observed to exhibit consistent Raman spectra which vary little in fixed (figure S2.D) compared to live cells (figure S2.C), and comparison with spectra of common lipids such as phosphatydylinositol (figure S2.E) and phosphatydyl-L-serine (figure S2.E) confirms that they are lipidic in structure, an obvious candidate being peroxisomes. Regardless of their origin, the main concern was the strong Raman scattering of these droplets and therefore the probable interference with the detection of nanoparticles in the cells. It was therefore deemed imperative to optimize the protocols for the cell sample preparation and to reproducibly obtain cells with similar morphologies.

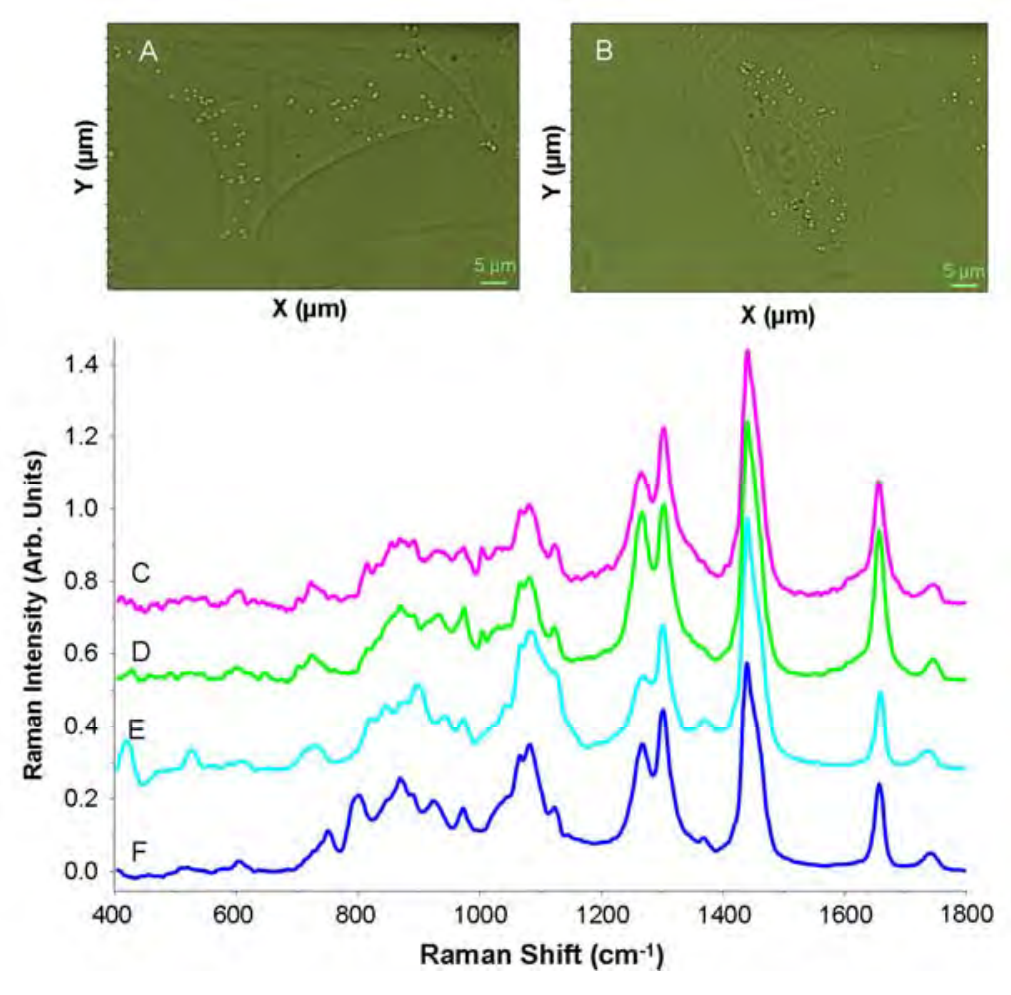


Figure S2: Microscopic images of live (A) and formaline fixed (B) A549 cells with "stressed" morphologies. Raman Spectra of droplets in (C) live cells (D) fixed cells compared to (E) phosphatidylinositol and (F) Phosphatidyl-L-serine. Spectra are offset for clarity

Different parameters have to be taken into consideration during the cell culture and the preparation of the samples. The cells are commonly split when they have reached between $80-85 \%$ of confluency in the cell culture flasks. However, performing a splitting when the cells were only about $60 \%$ confluent greatly diminished the number of the droplets per cell. Under such conditions, after a few splits, almost no droplets can be seen in cells either in the cell growth flasks or on the substrates used for confocal imaging or Raman mapping. Subsequently, the temperature of the PBS solution used to wash the cells has to be $37^{\circ} \mathrm{C}$, and it was further noted that the quality of the fixation can be affected by the temperature of the formalin used. Although, the formalin is usually kept at room temperature, warming to $37^{\circ} \mathrm{C}$ before fixation showed a better conservation of the cell morphology after fixation. Once the sample preparation procedures have been optimised, cells of consistently “unstressed” morphology can be routinely obtained, as shown in Figure S3. Fewer vacuoles or lipid droplets are evident, and there is a better definition of the endoplasmic reticulum (marked with arrows in figure S3). 

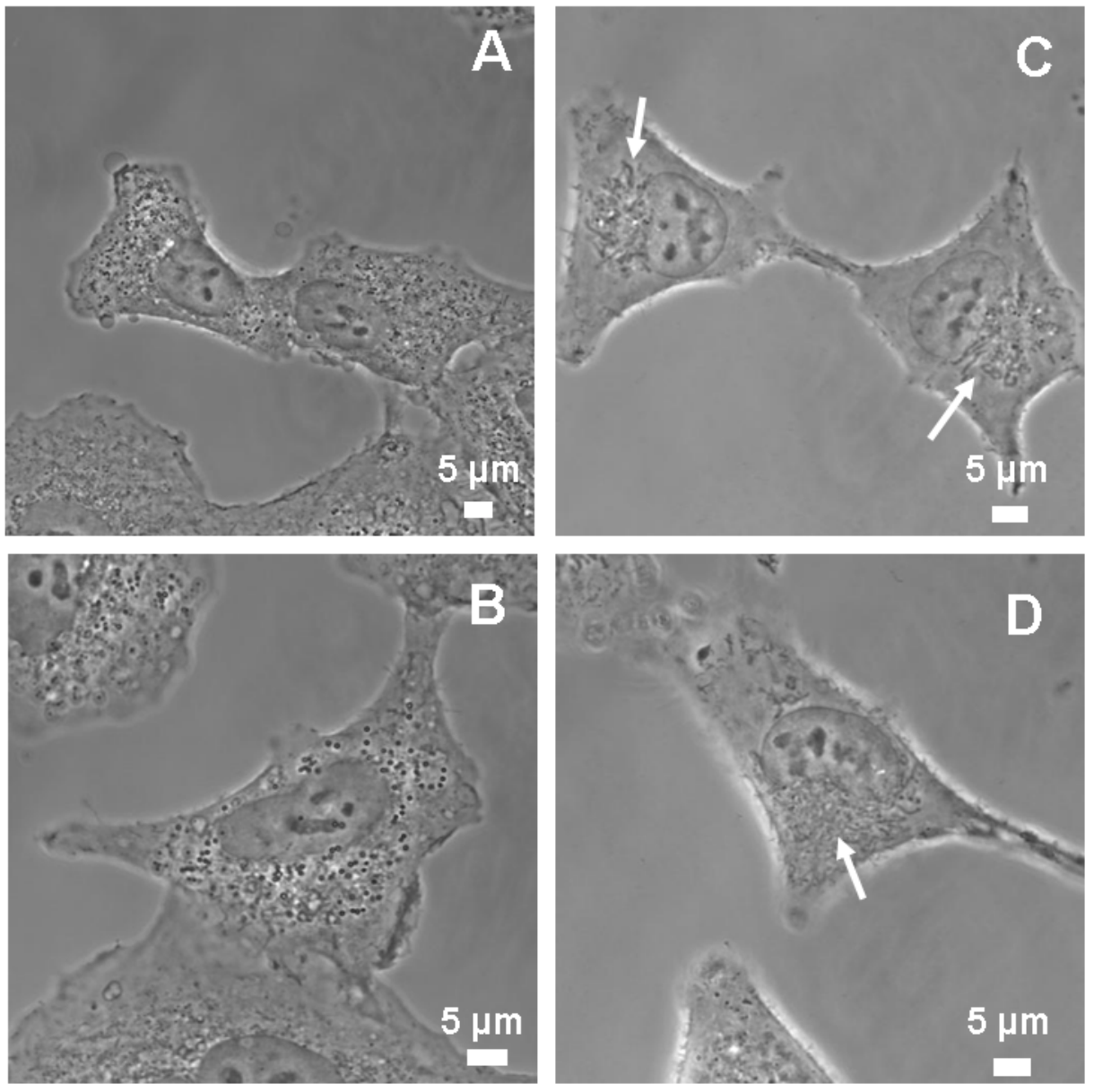

Figure S3: Microscopic images of cells with "stressed” (A, B) and “unstressed” morphology (C, D).

\section{S.4Effect of the cell fixation on the Raman spectra}

Mapping of single cells using Raman spectroscopy can be time consuming and, depending on the quality of spectra required, many hours are usually needed to complete a single map. As the viability of cells removed from an incubation environment is compromised, fixation of cells remains a popular option for extended measurements. Different approaches to fixation can be employed, including dry fixation, alcohol fixation or formalin fixation. These different methods have been recently compared by Raman 
spectroscopy ${ }^{4-6}$. In order to preserve the cell morphology, dry fixation has been excluded for this study, as the modification in the cell shape and thickness due to the drying will make comparison with live cells difficult. Formalin fixation is the more promising approach, as the cells are maintained in a hydrated state and, therefore, as close as possible to the living state ${ }^{4}$. Based on the observations made above, the protocols for cell fixation were optimised and the sample preparation standardised. Under these conditions, the localisation of the different subcellular organelles can be precisely visualised and Raman spectra recorded from similar structures more accurately. Figure S4 presents spectra recorded from the nucleus and cytoplasm from live and formalin fixed cells. The spectra exhibit similar intensities and no contribution from the $\mathrm{CaF}_{2}$ substrate can be seen. The spectral signatures obtained after fixation using formalin are identical to those recorded from the live cells. Using adapted protocols for the cell culture and fixation, the effect of the fixatives used can be greatly reduced.

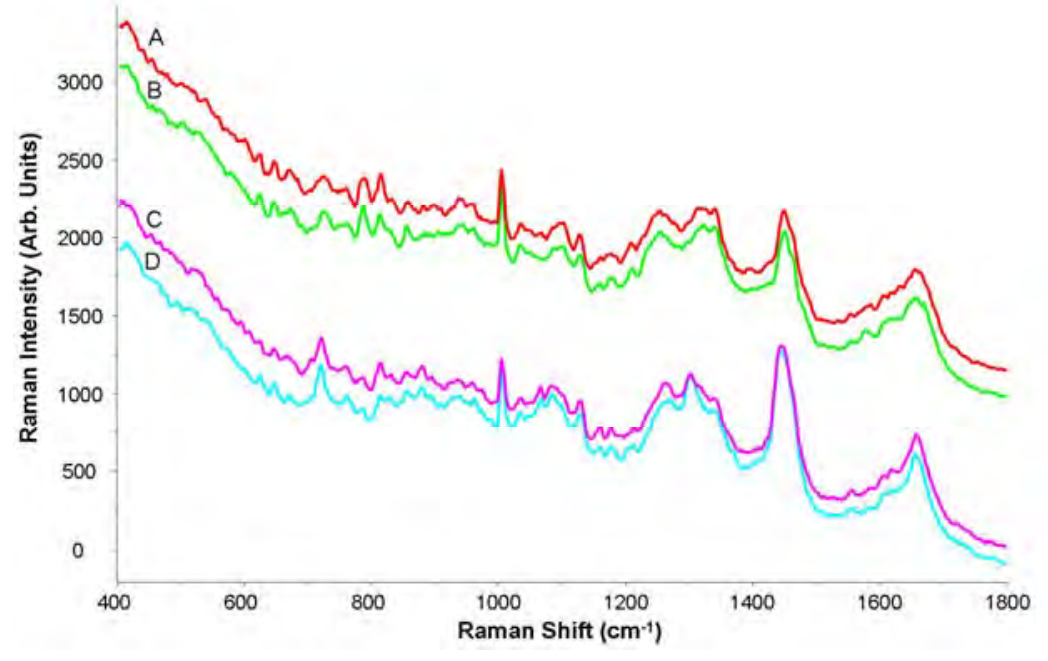


Figure S4: Raman spectra of the nuclear region of fixed (A) and live (B) cells and the cytoplasmic region of fixed (C) and live (D) cells. All Spectra have been recorded using the $785 \mathrm{~nm}$ laser source and are the result of two accumulations of 20 seconds per spot. Spectra are offset for clarity

\section{Bibliography:}

1. Lundqvist M, Stigler J, Elia G, Lynch I, Cedervall T, Dawson KA, Proceedings of the National Academy of Sciences, 2008, 105, 14265-14270.

2. Davoren M, Herzog E, Casey A, Cottineau B, Chambers G, Byrne HJ, Lyng FM, Toxicology in Vitro, 2007, 21, 438-448.

3. Ryman-Rasmussen JP, Riviere JE, Monteiro-Riviere NA, J Invest Dermatol, 2006, 127, 143-153.

4. Meade A, Clarke C, Draux F, Sockalingum G, Manfait M, Lyng F, Byrne H, Analytical and Bioanalytical Chemistry, 2010, 396, 1781-1791.

5. Draux F, Gobinet C, Sule-Suso J, Trussardi A, Manfait M, Jeannesson P, Sockalingum GD, Anal Bioanal Chem, 2010, 397, 2727-2737.

6. Mariani MM, Lampen P, Popp J, Wood BR, Deckert V, Analyst, 2009, 134, 1154-1161. 